Presented at the 1977 Nuclear Science

Symposium, San Francisco

LBL -6441

October 19-21, 1977

\title{
ZONE REFINING HIGH-PURITY GERMANIUM
}

G. S. Hubbard, E. E. Haller, and H. L. Hansen

October 1977

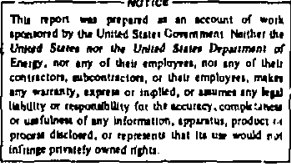




\author{
G. S. Hubbard, E. E. Haller, and H. L. Hansen \\ Lawrence Berkeley Laboratory \\ University of California \\ Berkeley, Callfornta 94720
}

\section{Abstract}

The effects of various parameters or. germanium purification by zone refining have been examined. These parameters include the germanium container and container coatings, ambient gas and other operating conditions. Four methods of refining are presented which reproductbly yield $3.5 \mathrm{~kg}$ gemanium ingots from which high purity ( $\left.\mathrm{N}_{\mathrm{A}}-\mathrm{N}_{0} \mid \leq 2 \times 10^{10} \mathrm{Cm}^{-3}\right)$ single crystals can be grown. A qualitatfve model involving binary and ternary complexes of $51.0, E$, and $A 1$ is shown to axcount for the behavior of impuritles at these low ioncentrations.

\section{Introduction}

High purity $\left(\left|N_{A}-N_{0}\right| \leq 2 \times 10^{10} \mathrm{c}^{-3}\right)$ single crystal gemanfum sultable for large volume radiation detectors has been produced in several laboratortes for number of years. 2,2 once 1 thas demonstrated by Haller, et.al."' that the zone refined germantuil was the source of all but one (P) of the impurities found in these crystais, a program to investigate the zone-refining process was begun.

The zone-refining process for gemantum as described by Pfann and others in the 1950's " " depends for its effectiveness on the nature of the equitibrtum between the solid and liquid phases of germantum in which impurities are dissolved. This relationship is usually expressed as the segregation or distribution coefficient $k$ a ratio trefween the fmpurity concentration in the solid phase to that in the liquid. Impuritjes with $k>1(B, S I)$ tend to remain in the solid phase and segregate in the opposite direction as zone travel. Host impurities in $\mathrm{Ge}$, however, have $k \sim 10^{-1}$ or less. They will move easfly with the liquid zone and be deposited in the last Ge to freeze at the "dirty" end of the bar. A few elemental impurities from Groups III and $V(A I, G a, I n, P)$ have segregation coefficients of about. I and will be removed more slowly.

This simple model of the zone-refining process can be applied for impurity concentrations down to the Intrinsic level $\left(-10^{19} \mathrm{~cm}^{-3}\right)$. At lower concentrations, thiz effective segregation coefficient of a number of impurities, ( $A 1, B, G a)$ does not remain constant, but approaches unity. Consequentiy, the impurity concentrations in our zone refined ingots do not reach the ultimate distributions predicted by Pfarn.

Identifying those parameters of zone-refining which produce "anomalous" segregation coefficlents has required the investigation of many possible conditions which are compiled in Table 1 . The number of comblnations of factors is quite large, so not all posstbilities have been covered in detall.

*This work was done with support from the U.S. Energy Research and Developinent Aditinistration.

Table 1. Zone Refining Parameters

A Container

1. Solid graphite

2. Carbon smoxe from butane on quartz

3. Carbon siloke from butare plus pyrolitíc carbon on quartz

4. Pyrolitic carbon on quartz

5. Silica smoke on quartz

6. Stitca smoke plus pyrolitic carbon on quarty

B. Amblent Gas
1. $\mathrm{H}_{2}+\mathrm{N}_{2}$ (fornting gas)
2. $\mathrm{H}_{2}$ only
3. $\mathrm{N}_{2}$ only

C. Crystallintty

1. Single crystal

2. Polycrystalline

0. Opersting Conditions

1. Speed of zone travel

2. Ingot length/zone length ratio

3. Position of zone start

\section{Experimental}

The primary measurement techniques used in this research were conductivity measurements at $77 \mathrm{~K}$, van der Pauw Hall effect, Photoelectric Spectroscopy (PES) $^{p}$ and Czochralski groweh of single crystals under controlled conditions. Most of the time, Hall effect measurments were performed at $77 k$, but to verify that the result at $77 \mathrm{~K}$ represented the shallow impurity concentration, several measurements were made from $300 \mathrm{~K}$ to $5 \mathrm{~K}$. In addition to these primary techniques, important information was provided by scanning electron microscopy (SEM). With the exception of SEM, our methods have been detailed elsewhere and will not be discussed in this paper.

The application of these experimental techntques to zone-refined material was a probiem in the early stages of this work since ail the Ge was polycrystalline. It was demonstrated recentiy by Hubbard, et.a1." that small single crystallites could be successfutiy located and removed from polycrystalline material and subsequently analyzed. Single crystal gemanfum growr. from polycrystalifine materlal demonstrated that impurity concentration values given by the crystallite measurements were representative. However, depending on random growth of sufficiently large crystallites for analysis proved risky in crucial expertments, so we found it necessary to return to the older techniques developed for zone-levellng. $8 y$ providing a [111\} seed at the zone start or "clean" end of an ingot, single crystal ingots were refined, thus simplifying the problem of analysis. Various 
techniques for doing this seeding are described in the itterature." 5 of the 104 ingots which make up the data base for this paper, 20 have been single crystal. Refining single crystal ingots also allowed us to examine the question of whether impurities are trapped at grain boundaries in pelycrystalline material. perhaps contributing to the non-sagregating nature of major impurities. All other consitions being equal, no difference has been found in impurity distribution between single crystal ingots with 5 to $10 \times 10^{3}$ etch pits/cm and polycrystalline gemantum.

Care was still exercisec' in measuring even single crystal ingots since the crystallography occaslonally became so severely disturbed that it affected the conductivity measurements. It was also found that lineages and high etch pit density could cause considerable difficulties in measuring the small $(.7 \times .7 \times$ $\left..2 \mathrm{~cm}^{3}\right)$ samples used in our varfable temperature $\mathrm{Ha} 11$ effect apparatus. A sample with poor crystallography would cease to give a meaningful midsurement at a temperature of around $30 \mathrm{k}$, probably due to the acceptor and donor liands created by dislocations. io Hall effect measurements perfomed over the whola temperature range showed no deep levels with the exception of occasionsi small amounts of $\mathrm{Cu}$ with an activation energy of 44 meV.

A typical zone-refined ingot measures about $60 \mathrm{~cm}$ In length including the seed $(8 \mathrm{~cm})$, and has a trapezoidal cross-section $2.5 \mathrm{~cm}$ high with a man width of $3.2 \mathrm{~cm}$. [The only exception are several ingots with a holf-circular cross-section of diameter $4.5 \mathrm{~cm}-\mathrm{th}$ is special case will be discussed later. I: During normal refining, our molten zone was about $3 \mathrm{~cm}$ long. Such a zone gives a ingot length ( $L$ ) to zone length $(R$ ) ratio of about $20: 1$. If $k \leq .1$, this ratio should have produced an ultimate impurity distribution witi: a very steep gradient after many passes. Because most terhniques of zone refining high-purity Ge do not show strong segregation $(k-1)$, ittile work has been done on the influence of the L/e ratio. The speed of zone trivel, recommended by Pfann and others to be .8 to $8.5 \mathrm{~cm} / \mathrm{hr}$ for the best resistivity untformity and crystal per. fection, was usually $10 \mathrm{~cm} / \mathrm{hr}$ in our work. Some refining was done at $3 \mathrm{~cm} / \mathrm{hr}$ and while the crystallography of the ingot was mach better no differences could be observed in the impurity distribution.

By far the most significant factor studfed in our zone-refining research has been the influence of the material in contact with the gemantum. The atmosphere diring refining also plays a role, but unless stated otherwise, one may assume a "fonming gas" mixture of $90 \% \mathrm{~N}_{2}$ and $10 \% \mathrm{H}_{2}$.

Since germanitum wets quartz and will stick upon freezing, bare quartz containers cannot be used for zone refining as it can in crystal growing where the entire melt is removed as a crystal. The alternatives. are to use a solid graphite boat or to coat the quartz.

The detailed preparation of the coatings as we? 1 as the cleaning of the germantum are given in the Appendix.

\section{Results and Discussion}

\section{A Model of Complex Formation}

Evidence provided by zone refining and crystal growth has led us to construct a model of impurity behavior which involves binary and ternary complexes of silicon, oxygen, boron, and aluminum. This model

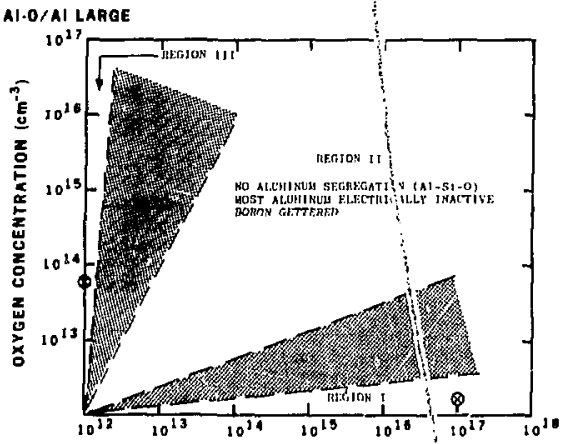

AI.O/AI SWALL SILICON CONCENTRATION (Cח

Ho: $\% 10-1005$ ?

Fig. 1 Dur tentative qualitativa model of th" affect of silicon and oxygen on uluminum and boron is shown. In Region i where siliticon i: domfnant, the impirities segregate. Reרfoi: II represents the conditions of crystal griwth from quartz and silica zone refininy. . Region III, oxygen is dominant and electiti. cailly active impurities segregace. As tha amount of oxygen increases, more impuritils become electrically inactive $(A)-0, B-0)$.

is an extension and modification of that presented in an earlier paper. ${ }^{3}$ for purposes of clarity, it is i presented first $(\mathrm{F} / \mathrm{g}, 1)$, and we shall see later hom the results of zone refining and crystal growth experimeits fit the picture.

In Fig. 1, the cotal concentration of aluininum or boron in a meit or zone is considered to be constant The material in concact with the gemanium is not directly relevant; although, as we sha 77 see, each container considered may be represented by one of the regions.

Region I is characterized by an Increasing sillcon concentration and low oxygen concentratior. At even very high sillcon concentrations, normal segregation of aluminum and boron occurs and almost all of the aluminum and boron is electrically acifve. In Regiali III, the concentration of silicun is low and the ancunt of oxygen increases. Here the behavior of al uminusis and boron is more complex, but in general the electrically active impuritic, stili segregate nomally. At very high concentrations of oxygen, $B$ and $A 1$ completely disappear due to the creation of electrically inactive Al-0, B-0 complexes. This was demonstrated by the work of Edwards. ${ }^{12}$ At intermediate leve1s af oxygen, both electricaliy active and inactive impur'ties exist. The electrically active form segregates nomaliy, whereas the electrically inactive impuritij-oxygen complex seems to have $k w_{1}$. Most high-purtty genmanium crystals are grown under the conditions of llegion II. In this region, silicon and oxygen are present in approximately equal quantities, creating $5 i-(j-(A), B)$ complexes. Electicically active aluminum does not segregate and a large fraction of aluminum is in the form of electrically inactive 
complexes. Boren is largely gettered by complex formation.

Impurity Behavior During Single Crystal Growth

The importance of the container for high-purity single crystal growth was made clear by Hall and Haller, et.al. " They showed that aluminum in the starting charge sagregates numally when single crystats are grown from a graphite crucible or pyrolitic carbon coated quartz crucible but does not segregate in a bare quartz crucible. Furthemore, the elect-ically active aluminum concentration of a given crystat will appear to increase by about a factor of $6-10$ if it is grown in a sarbon container rather than quartz. This increase is reversible and demonstrates that most of the aluminum in a crystal grown from bare quartz is not elecirical]y active.

\section{Buron, which may be present at concentrations} $\sim 10^{1:} \mathrm{cm}^{-3}$ in the starting material, will remain electrically active if the meit is contained in pyrolitic carluon but will largely disappear if tine crystal is puiled from a quartz cructble. This reduction, which cin be as much as a factor of 100,15 irroversible in the sense that regrowing the quartz cructble crystal in carbon will not make the boron reappear.

An explanation of such impurtty behavior was suggested by the worl: of Edwards 12 when he d. monstrated that electrically Inactive complexes of Al and $B$ with $\mathrm{O}_{2}$ can be fomar nuring erystal growth from graphite crucibles. At the time, however, the role of stlicon was not fully appreciated except as a componerit which might explain the discrepancy between Edwards' observations of boron and our own.

It was shown that at a level of $\sim 10^{17} \mathrm{~cm}^{-3}$ stllcon in a single crystal grown from a Suprasil quartz crucible alumfnum segregates. Aluminum aiso segregates in crystals containing oxygen at concentrations as high as $6 \times 10^{13} \mathrm{~cm}^{-3 *}$ as iony as the quartz crucible is isolated from the Ge melt by a pyrolitic carbon layer. Such a case is shown in Fig. 2 (Crystal 495). The high level of oxygen can be accounted for by the nonreducing atmosphere of $\mathrm{N}_{2}$ present during cyrstal

growth. These two results fall into Regions I and III, respectively, on Fig. 1 and are indicated by 8 . They show that if one can shift the $5 i / 0$ ratio very much in one direction or the other, aluminum can be forced to segregate. At very high levels of oxygen a lone, as in Edwards' case, $B$ and Al disappear in electrically inactive binary complexes. However, as long as concentration of oxygen is about that commonly encolintered during high-purity crystal growth $\left(6 \times 10^{\gamma_{3}}\right.$ $\left(\pi^{-3}\right)$, and no silicon is present, segregation of electrically active impurities will occur. Once silicon is introduced, the impurity behavior switches to Region Il where $S f-0-(1), B)$ complexes occur. Then, the electrically active aluminum ceases to segregate (one observes flat aluminum profiles) and boron is gettered.

The disappearance of boron when crystals are grown in quartz can be explained by the formation of glasses. Doremus it points out that borousilicate systems can be formed at temperatures as low as 500 $600^{\circ} \mathrm{C}$, far below the melting point of germanium. By introducing silicon from a quartz boat, silica coating or crucible, an effective gettering mechanism could occir. Alumina-silicate systems such as ceramics accur at higher temperatures but may be similar to the

\footnotetext{
"Oxygen concentration is measured by the 11 thium preci-
} pitation method. ${ }^{3}$

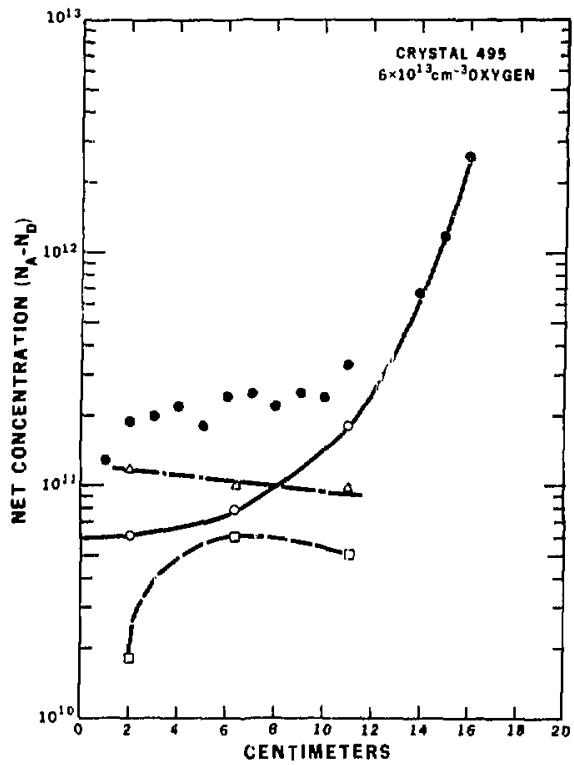

18L. $710 \cdot 1003$

Fig. ? Grown from a pyrolitic carbon quartz crucfble under a nitrogen atmosphere, Crystal 495 was determined to have $6 \times 10^{13} \mathrm{~cm}^{-3}$ oxygen by a lithium precipltation measurement. Points marked with represent net acceptors, $O$ indicates aluminum, $\Delta$ is acceptor $A_{4}$ and is acceptor $A_{5}, A_{4}$ and $A_{5}$ disappear upon annealing and appear to be related to the presence of nitrogen. The activation energies are very close to those of boron and gallium, respectively.

type of complex formed in the Fegion II of Fig. 2. The optifium conditions for segregation and zone purification should then be a low oxygen, low silicon environment such as a graphite container with hydrogen.

\section{Zone Refining in Graphite and Carton Coated Quartz}

Early gemanium zone refining was done in solid graphite boats and today such containers are routinely used by commercial suppliers of "Intrins ic" grade germanium. Analys is of test crystals t* grown directly from Eagle-Picher $40 \Omega \mathrm{cm}$ intrinstc gemanium showed that boron and phosphorous were usually quite high, with both in the range of $10^{13}$ to $10^{i 3} \mathrm{~cm}^{-3}$. The

**Un]ess otherwise stated, it will be understood that all single crystals are grown by the Czochralsk? method from a Suprasil quartz crucible under a pure $\mathrm{H}_{2}$ atmosphere using cleaning procedures and techniabes described in previous publications. $\theta$ 
aluminum content varled but in the test crystals it was observed to be $3 \times 10^{10} \mathrm{~cm}^{-3}$ to $-10^{11} \mathrm{~cm}^{-3}$. When such intrinsic grade starting material was further refined In solid graphite boats at our laboratory, an impurity distribution such os that of Ingot 90 (Fig. 3) was observed. The impurtty seen segregating toward the zone start and maintaining the high $\left(\sim 5 \times 10^{11} \mathrm{~cm}^{-3}\right)$ background is boron. The constant level of boron seen in graphite boats and carbon coated quartz boats indicates that carbon is a source of boron. However, the low silicon, low oxygen environient of the graphite bost allowed the aluminum in the intrinstc material to segregate. As a resuit, crystals subsequently grown from materlal refined in graphfte were low in Ai but, the boron contanination was too grest to be adequately gettered by complex formation.

Ingot 91, (F/g. 3), was first refined in a solid graphite boat then placed in a butane smoked quarti boat for about 20 passes. Single crystal growth and electrical measurements isve demonstrated that both Ingots 90 and 91 contain about the sarie amount of aluminum though Ingot 90 secms to have substantialiy less boron. The factor of 10 difference in impurtty concentration can be explained by complex fomation Involving boron, oxygen. and silicon as demonstrated for single crystals.
We assume that the amorphous carbon smoke, in contrast to the much denser pyrolitic carbon, did not prevent the liquid germanium zone from interacting with the quartz boat. Silicon and oxygen contributed from the quartz then combined with the boron to form bori-silicates.

SEH has provided proof of the porousness of these smoke coatings. An exaisization of coatings of pyrolitic carbon on smokt (either sllica or carbon) showed that a pyrolitic coating on the surface of the quartz. boat nearest the germanium can be formed through the the smoke layer.

"Doublg" zone refining was then found to produce acceptable starting materla?. By first refining uncer low oxygen. How sillicon conditions to make aluint num segregate and then refining in some environment where borun could be gettered by $51-0$ complexes al1 impurities could be reduced to low levels.

ingot 121, refined in a coating of pyralitic carbon and carbon smoke bears a strlking resemblance to Ingot 90 , again demionstrating that whon one separates the gennantum from puartz so that si-0 complexes cannot form, boron is not gettered and alumitnum segreages. The distribulion of all p-type impurities as

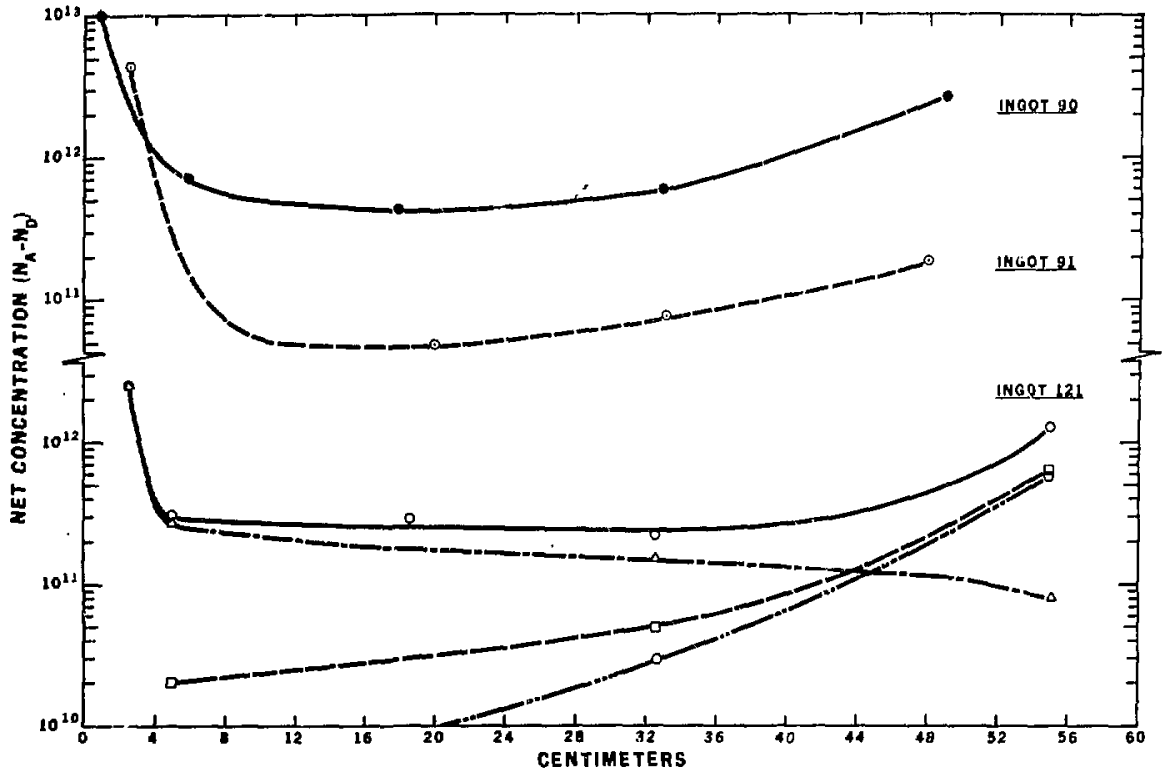

XBL 7710-10059

F1g. 3 Ingot 90 has been refined in a solid graphite boat. inyot 91 has been first refined in solld graphtte then in a quartz boat smoked with carbon from burning butane. Ingot 121 was refined in a boat coated with carbon stake then pyrolitic carbon. $O$, - and $O$ represenz net acceptors, $\Delta$ indicates boron, aluminum and $O$ gallium. All ingots are polycrystalline. 
detemined by PES and Hail effect is shown for Ingot 121 . As with Ingot 90 , boron segregates towards the zone start and also has an almost constant res $j$ dual concentration of $-2 \times 10^{11} \mathrm{~cm}^{-3}$. Aluminum segregates into the "dirty" end of the ingot but the distribution in the bulk of the ingot does not follow the ultimate distribution given by Pfann. He explain this by a high-oxygen concentration in the absence of stlicon which creates an electrically inactive, nonsegregating Al-0 complex. Crystals grown from Ingot 121 under low oxygen, low silicon condtitions show that most of the aisminum is electrically fractive, indicating that the concentration of oxygen is at least. $6 \times 10^{13} \mathrm{~cm}^{-3}$ or higher."

During each zone pass through lngot 121, the electrically active portion of the aifunt num segregated but the Al-O/Al ratto re-established in the frazen gernanfum behind the moving zone left some new fraction of electrica?ly active aluminum. Thus, the impurity proflle did not reach the ultimate distribution. Refining with pyrolitic carbon/anorphous carbon coated quartz under pure hydrogen rather than ioning gas atmosphere has not yet proved successful in reducing the concentration of aluminum to lower livels. This may be due to oxygen in the amorphous carbon smoke.
Since we believe that during single crystal growth from a pyrolitic carbon quartz crucible under hydrogen atmosphere, there is very little oxygen and probably no silicon present, the obvilous extension would be to refine under such conditions. The technological difficulty is that molten germanium wets pyiolitic carbon coated quartz, dllowing the solidified germanium to adhere to the walls of the boat. If the germanium cannot sitide in 1 t:s container as the themal expansions and contractions occiur, the boat witl break as the germanium pushes against one end. Recently, we have found that by selecting very smooth quartz tubes with uniform inner diameter $(45 \mathrm{~mm})$, closing off the ends i: rounding, then slicing lengthwise, halfcylinder boats car be made in which refining can be done. The glassy pjrolitic carbon on smooth quartz with no constriction in diameter allows just enough slippage in short "Jumps" to keep the boat from breaking. Expertments with boats of this type are in the initial stages 50 results are still forthcoming.

\section{Zone Pefining in Stlitca Coited guartz}

Anotlier approuch to the search for effective zone refining has been the use of sillca smoke as a boat coating. Made by burning silane as describod in the

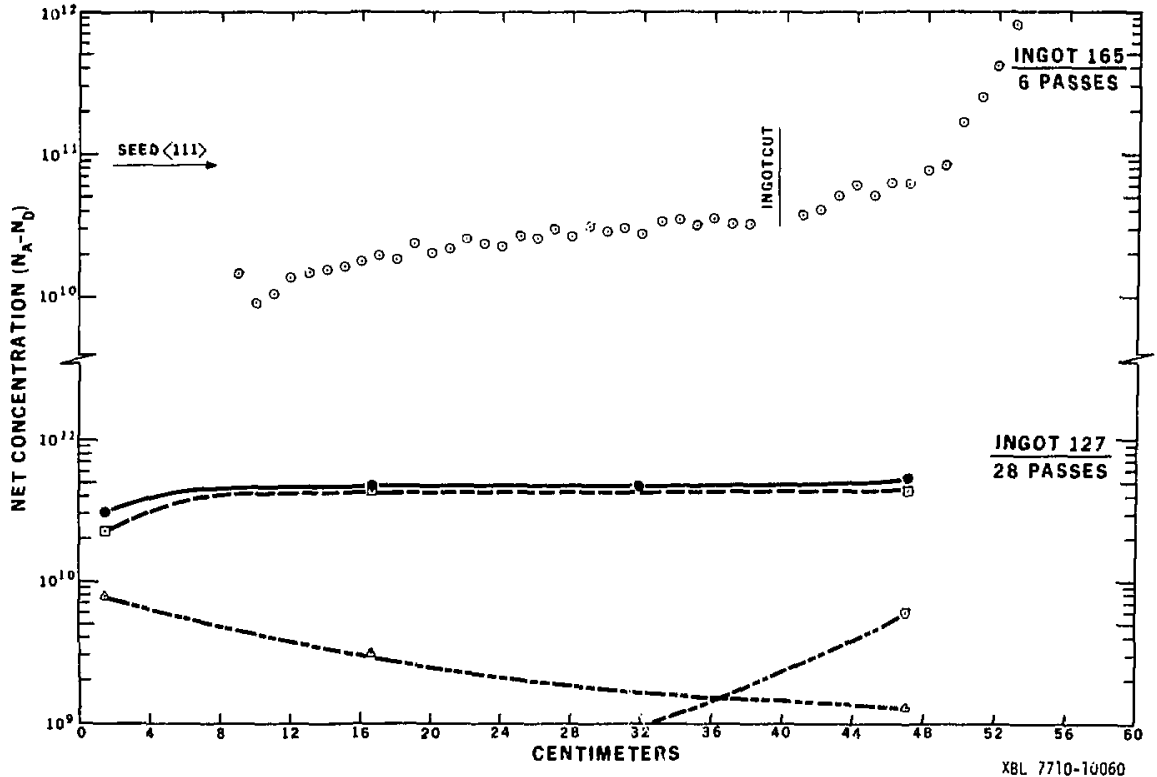

Fig. 4 Ingot 165 is single crystal, refined in a silica smoked quartz boat. $\odot$ represents net acceptors as measurer by conductivity. Ingot 127 is polycrystalitine, refined in a sllica smoked quartz boat. indicates net acceptors, $\square$ represents aluminum, $\Delta$ boron, and $O$ gallium.

\footnotetext{
FAttempts to measure the oxygen in samples taken from polycrystalline material have yitelded inconsistent results, possfble due to poor crystaliography.
} 


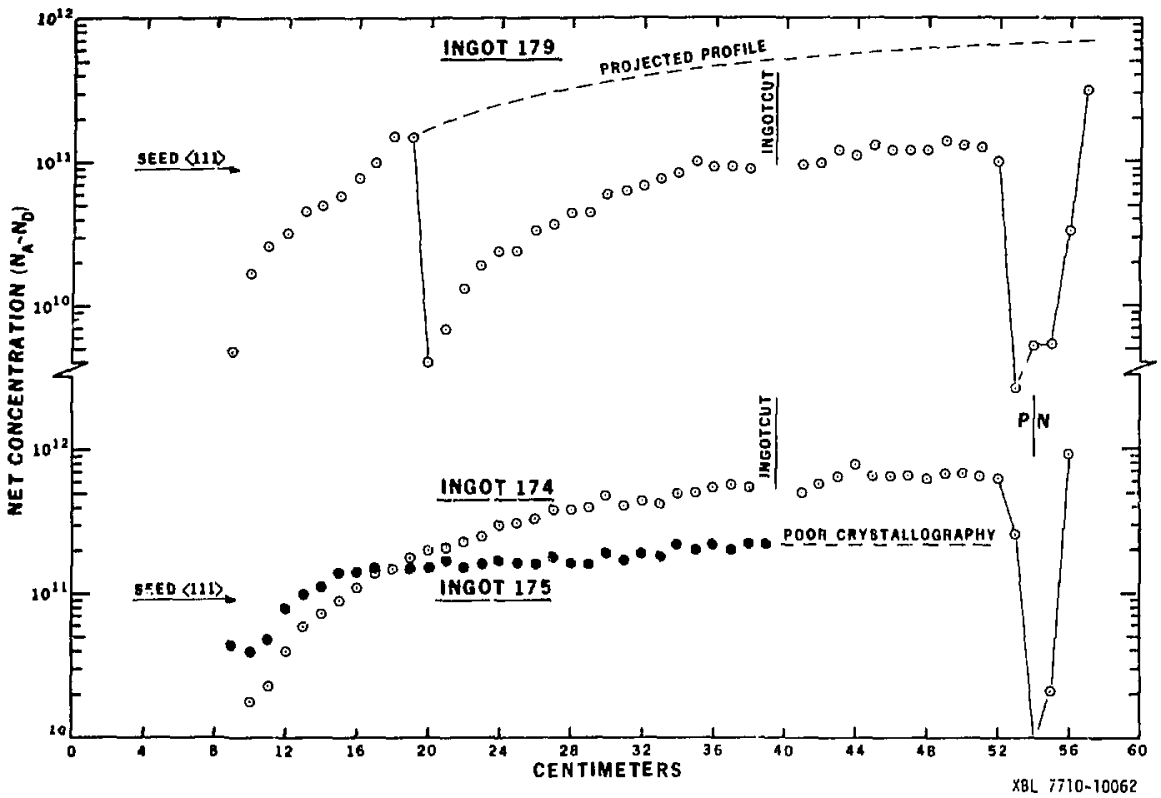

Fig. 5 Ali ingots are single crystals. $\odot$ and - both represent net acceptors. Ingot 179 was given five passes in a silica smoked boat, removed, the sflica replaced and given five more passes from $20 \mathrm{~cm}$ to the end. Ingot 174 was given five passes in a silica smoked boat, removed, analyzed, etched, and replaced into the same silica coating. After five more passes, the ingot, now called 175, was ramoved and measured to the point where poor crystallography began to disturb the measurement.

Appendix, the smoke consisted of $\mathrm{Si}$ and $\mathrm{Si}_{\mathrm{x}} \mathrm{O} \mathrm{y}^{\text {. Most }}$ itkely the 5i/O ratia is sightly in favor of the silicon, 1.e., the Impurity behavior should be in Region II but nearer the $x$-axis and Region I. Cons iderable work has been done with this coating for two reasons: 1) Ease of analysis: The white coating gave a $5 \mathrm{ma} 11$ themal gradient at the melt/solid interface in the zone refiner, yielding large crystallites in polycrystalline ingots and facilitating seeding in single crystal ingots. 2) High purity: This costing has yielded consistently high-purity ingots, although single step zone refining is not always suffictent.

Figure 4 shows two typical Ingots, 127 and 165 , refined from the less pure sections of other ingots. There is little difference in impurity concentration between the single crystal and polycrystalline material or between 6 and 28 passes of the moiten $20 \mathrm{ne}$. Ingot 127 has a "flatter" Impurity profile while 165 shows a slightly "sloping" profile with some accumulation in the tafl end. From PES data, we found the tajar impurity in the silica smoke ingots to be a] int num with smali amounts of horon and gallium. PES measurements have also determined that slight segregation of aluminum in Ingot 165 makes the inpurity profile rise slowly in concentration. This effect is consistent with the hypothes is that the presence of excess silicon allows some segregation. However, most purification takes place in a few passes so a mechanism such as gettering by complex formation rather than segregation must be dominant.

Figure 5 shows a cast ingot (174) of intrinsic grade commerical germanium refined for live zone pas'ses. After removing the ingat and measuring the concentra. tion it was etched, exposing a new surface. The injot was returned to the same coating for five more passes and a further reduction of $\mathbf{2 . 5}$ in impurity concentiawas achieved (Ingot 175). Ingot 179 was also a cast ingot of $40 \Omega \mathrm{cm}$ germanium refined for five passes. The ingot was carefully removed but not etched and nily the silica smoke coating replaced. By moving the position of zone start, enough of the initially refined gemanium could be preserved to determine the proftle after the first five passes. The balance of the ingot, unetched but in contact with a fresh coating exhibited a drematic 5-fold drop in impurity concentration. Taken together, these two experiments demonstrate that a vigorous gettering by complex formation occurred at the gemanium/silica coating interface. No change in the shape of the impurity profile was noted, as would be the case with segregation, but etching the ingot and replacirig the silica coating effected large reductions in the impurity concentration.

Using this gettering action, one can consistently produce qenmanium of suffictently high purity for detector grade crystals to be made in a single pult. 


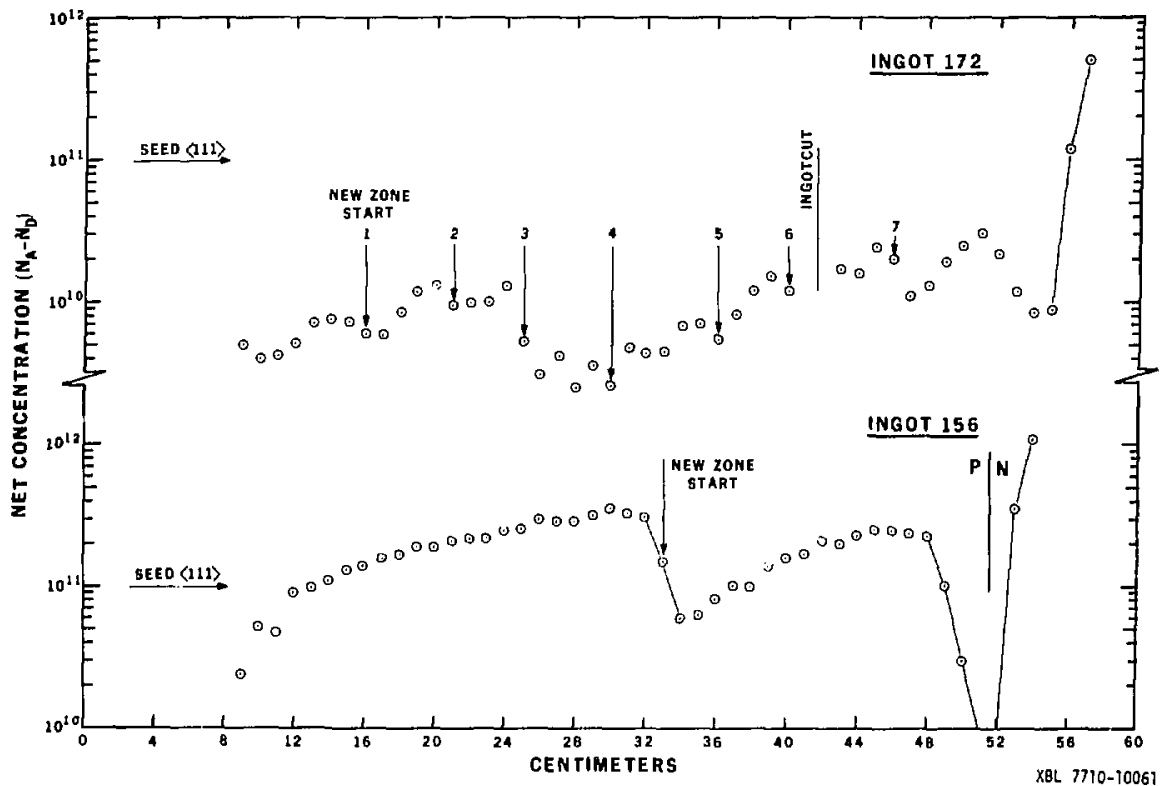

Fig. 6 Both ingats are single crystal. $\odot$ indicates net acceptors, Ingot 156 was refined eight passes in a silica coated boat, then a new zone was begun at $33 \mathrm{~cm}$ and passed to the end. Ingot 172 was refined four passes in a silica coated boat then a sequence of seven new zones were passed to the end. Each new zone was begun about $5 \mathrm{~cm}$ closer to the end.

If one begins with intrinsic grade gemanium, the process requires two separate refinings in which the ingot is etched and the silica coatings replaced. A final equilibrium between electricaliy active and complexed impurities appears to be established at a measured impurity concentration of 1 to $4 \times 10^{10} \mathrm{~cm}^{-3}$. As a result more etching and new coatings do not further improve the impurity concentration. If the ingot has been first refined in a graphite or pyrolftic carbon/ carbon smoke environment, a subsequent refining in sillca smoke usually easily renoves the boron in a few passes.

While investigating the silica coating, it was observed that all such ingots had a characteristic "dip" in concentration wherever a zone was begun. This effect is shown in Fig. 6, Ingot 156. The "dip" was observed only when hydrogen (either as pure $\mathrm{H}_{2}$ or

forming gas) and silica smoke were both present. No dip was seen with pure nitrogen or when one refined with one of the carbon coatings. Furthennore, just stopping the zone travel in the middle of an ingot did not produce a dip. A new zone had to be started in solid gemanium. The difference between a "starting" zone and a "moving" zone gepends on the fact that some segregation cccurs when a zone begins, but an equitibrium between impurity complexes is the meit and the coating is soon reached. No further gettering and little segregation then occurs as the zone moves to the end of the ingot.
By restarting the zone in a offferent place, the impurities in the melt had a chance to segregate befure a new equilibrium was established.

Ingats such as 172 Fig. 6 were then produced by making many zone starts. The majortty of the ingot is in the range of $5 \times 10^{9} \mathrm{~cm}^{-3}$ to $1 \times 10^{10} \mathrm{~cm}^{43}$; the dominant impurities still being aluminum and some boron, Crystals grown from this type of material have not consistentiy reflected such extremely high purity, however. A few crystals have been nearly all n-type, Indicating that residual acceptor impurities are conpensated by the phosphorous from the Suprasil cructbles. Other crystais have nat been substantially purer than those grown from germanium refined in silica smoke without the extra zone starts. It may well be that the muti-start technique increases the degree to which the impurfties are complexed beyond the point than can be sustalned during final crystal growth.

Figure 7 displays Ingot 187, refined in a pyrolitic carbon/sflica smoke cisating whtch combines the aluminum segregating envfronmint of carbon refining with the boron gettering property of silica. This coating has allowed us to successfutiy purtfy the commercial gemanfum in one s'sep. From analyzing ingots and studying the coat'ng with SEM. it appears that: 1) the presence of the ryrolitic carbon reduces the silicon contribution by covering the quartz boat walls and surrounding the silica smoke with carbon. This effectively moves the refining environment, near Region III 


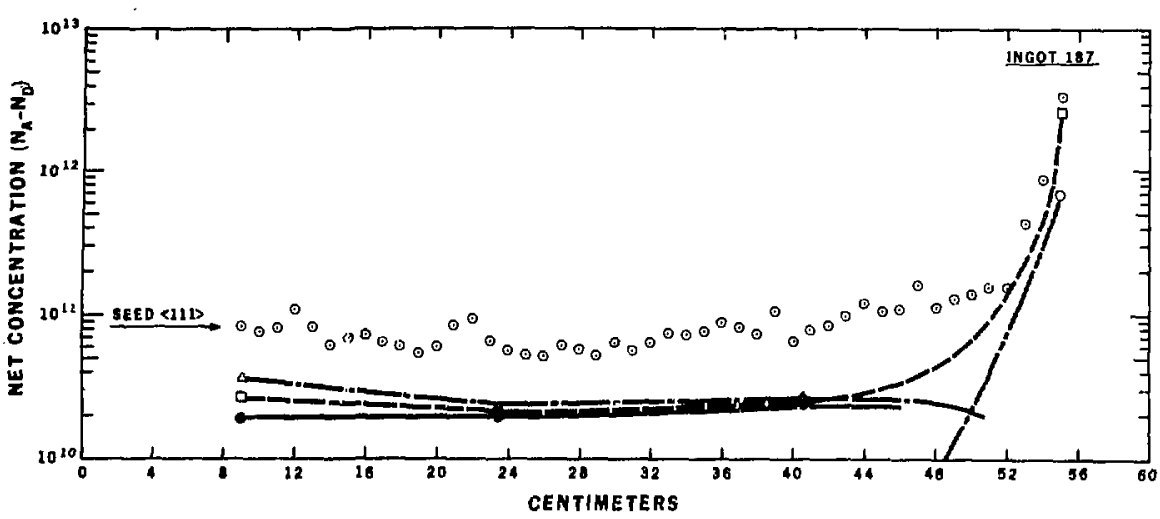

XDL $7710-10063$

Fig. 7 Ingot 187 is a single crystal, refined 12 passes in a pyrolitic carbon/s1ica coated boat. 0 represents net acceptors, $\Delta$ indicates boron. $\square$ represents bluminum, $A_{6}$ and $O$ gallium.

where segregation can occur. 2) The intlmate contact between the s1]1ca and carbun makes posstble borosilicate foriation, effectively remouting most of the boron contributed by the cerbon.

The starting moterial for Ingot 187 was intrinstc grade germanium whose aluminum content can be seen segregating into the end of the ingot as in Ingot 121 . The major difference is that the presence of the stilica amole has kept the boron to a level easily removed in final crystal growth. A new acceptor, identified by Hal?er ${ }^{5}$ as $A_{6}$. also contributes to the measured impurity concentration. This acceptor, which is seen quite often in the presence of pyroittic carbon and hydrogen, will disappear Juring single crystal pulling. Its presence is a reminder to not assume that a 11 observed impurity concentrations are related to the comion substitutional elemerits and points out again the power of PES as an analytical tool for semfconductors.

Crystais grown from Ingot 187 have been $p$-type and consistently in the range of $1-3 \times 10^{10} \mathrm{~cm}^{-3}$ at the seed end with a junction of $30 \%$ to $50 \%$ of the melt frozen. Refining similar ingots under a pure hydrogen atmosphere has teen recently attempted but the results are st111 forthcoming.

\section{Summary and Conclusign}

A qualitative model (Fig. I) Involving ternary and binary complexes of silicon, oxygen, baron, and aluminum has been presented to account for most of the behavior of the impurities observed during single crystal growth and zone refining of high purtty genmanium. At least four different methods of refinting commerclal $40 \Omega \mathrm{cm}$ to sufficient purtty for detector grade single crystals have been found:

1) Refining in a solid graphite boat followed by refinting with anorphous carbon smoke on quartz.

2) Pyrolitic carbon/carbon smoke refining followed by stlica smoke refining.

3) Sllica snoke refining repeated.

4) Pyrolitic carbon/silica smoke refinting alone.

Further breas for investigation invulve reducing the oxygen content during refining so that higher levels of purity can be reached and attempting to understand the nature of the new acceptors such as $A_{6}$ which have appeared in both zone reffned and sfingle crysta? material. We feel that the understanding of highpurity germanfum is now at the pofnt where the consistent production of large amounts is feastble.

\section{Acknowledgments}

We would 11ke to thank P. L. Richards, University of California at Berkeley and Materlals and Molecular Research Diviston, LBL for the use of the Fourier Transform Sptctrometer in our PES studies. We also would like to thank F. S. Goulding for his continuous interest in this work.

\section{Appendix}

1. Cleaning of quartz boats and ingots:

Prior to applying any new coating, the quartz boat is first etched by spraying a mixture of $3: 1$, $\mathrm{HNO}_{3}$ :HF to renove any resifual germantium as well

as the old coating. Following a distilled defonized water (DDW) rinse, the boat is then etched with HF alone, rinsed again with OOW and then dried with a boil off $\mathrm{N}_{2}$ jet.

The ingot is treated much as in the preparation for orowing a final crystal. First, the charge is spray etched with $3: 1$ as above to po! ish any sawed areas, rinsed with DDW, then etched again 
with $5: 1: 1 ; \mathrm{DOW}: \mathrm{HCl}: \mathrm{H}_{2} \mathrm{O}_{2}$. Another OOW rinse follows, then the ingot is blown dry with $\mathrm{N}_{2}$. Any subsequent handling is usually done with clean, dry filter paper.

11. Quartz boat coatings:

\section{A. Carbon smoke}

An etched boat is inverted and placed in a dust free enclosure while a flane of butane from a Bunsen burner is passed underneath. If one positions burner and boat so that the tip of the flame just touches the quartz, a coating of smoke should be produced. It is important to continuously mave the burner with respect to the boat to assure the uniformity of the coating. Or.e drawback of this type of coating is that the deposition is done in room air which could result in organic compounds and particulates being deposited along with the amorphous carbon.

\section{B. Pyrolittc carbon}

The production of a pyrulitic carbon layer is utilized for a number of coatings: pyroittic carbon on bate quartz, on butane smoke and on slllca smake. A quartz boat, etched or sultably coated is placed into a quartz tube surrounded by a resfstase heated furnace. The tube is evacuated and pumped continuously as the temperature is brought to $1100^{\circ} \mathrm{C}$. This procedure was instituted in an attempt to remove any outgassing oxygen or other volatiles.

After stablizing the temperature, pumping is discontinued and methane is introduced to a partia? pressure of .7 atm. The decompos 1 $t$ ion of $\mathrm{CH}_{4}$ at $1100^{\circ} \mathrm{C}$ for $1 / 2$ hour coats the boet with a pyrolitic carbon. Only one or two such treatments are necessary to produce a satisfactory coating--further applications tend to increase the amount of amorphous carbon created at cooler spots in the fu:nace. This additional amorphous carbon is the most pernicious problem in producting a truly pyrolitic coating. Scanning electron microscope studies of multiple layer coatings such as pyrolitic carbon on silica smoke fndicate that the methane penetrates the silica smoke and forms a pyrolitic carbon on the not quartz boat as well as encapsulating the silica smoke. In addition, a layer of amorphous carbon is deposited on top of the existing layers which then appears to act as a source of additional boron and possibly oxygen. One cure for this difficulty may be to introduce the methane in much smaller quantities.

A pyrolitic carbon coating can be removed by: 1) Etching: (This requires that the coating be underetched and floated away since few etchants will attack the carbon directly.) 2) Eurning: (A gas/oxygen torch in air will heat the carbor sufficiently that it witT oxidize--though this risks contamination of the boat from the torch.) 3) Oxidation in the furnace: (8y placing the used boat back into the furnace heating and introducing air or $\mathrm{O}_{2}$, the carbon can be oxidized as with the torch. ?

C. Silica smoke

As described in an earitier paper, " silica smoke is produced by burning silane ( $5 \% \mathrm{SiH}_{4}$ in hydrogen) ustng a triaxial quartz burner which mixes $\mathrm{SiH}_{4}$ and $\mathrm{O}_{2}$, using Ar as a separating gas blanket to keep the flame away from the burner tip. As in applying the butane smoke, the tip of the orange flame should just touch the bare quartz boat. If one is too close yellow-brown spots of silicon will form; too far away and no smoke will de deposited. Constant motion is also required to avoid overtieating any one spot and to ensure a uniform: coating of $20-50 \mu$ thickness.

The use of a laminar flow hood for this type of coating has been employed to reduce the likelihood of contaminating dust particies being incorporated into the silica smoke. The hood and protective clothing such as long rubber gloves and particulate filtering mask are also necessary to ensure the sarety of the person dolng the coating. Sllane itself is quite poisonous and the silfca smoke produces in the process can cause extreme lung damage if inhaled.

A used stilica smoke coating 15 easliy removed by ctching with $\mathrm{Z}: \mathrm{li} \mathrm{HNO}_{3}: \mathrm{HF}$.

\section{Reforences}

1. R. N. Hall, 1EEE Trans. Nuc1. Sc1., NS-21, No. I, $260(1974)$.

2. H. L. Hansen and E. E, Halier, IEEE Trans. Nucl. Sci.. NS-21, No. 2, 251 (1974).

3. E. E. Haller, H. L. Hansen, G. S. Hubbard, and F. S. Gouldíng, IEEE Trans. Nucl. SCt., NS-23. No. 1, 81 (1976).

4. W. G. Pfann, Zone Melting, John Wiley and Sons, New York $(196 \overline{6})$.

5. H. E. Bridges, J. H. Scaff, and J. H. Shive, eds., Transistor Technology. Vol. I, D. Van Nostrund (1958).

6. L. J, van der Pauw, Phllips Research Reports, 13, $1-9(1958)$.

7. E. E. Haller, W. L. Hansen, and F. S. Goulding, IEEE Trans. Nuc1. Sc1., NS-22, No. 1, 127 (1975).

8. W. L. Mansen, Nuc7. Inst. and Methods, 94, 377 (1971).

9. G. S. Hubbard, E. E. Haller, W. L. Hansen, Nucl, Inst. and Methods, 130, No. 2, 481 (1975).

10. D. Hergel and R, Labusch, Phys. Stat. Sol. (a), 41, 431 (1977).

11. $40 \Omega \mathrm{cm}$ Intrinsic Grade Germantum, Eagle-Picher, Co., Quapaw, Okiahoma.

12. W. D. Edward5, J. Appl. Phys., 34, 2497 (1973). Also, J. Appl. Phys, 39, 1784 (1968).

13. R. J. Fox, IEEE Irans. Nucl. SC1., N5-13, No. 3, $367(1966)$.

14. R. H. Du nus, Glass Science, John Wiley and Sons, New York (973).

15. E. E. Haller, lst Seminar on Photoelectric Spectroscopy of Semiconductors, Moscow (1977). 